\title{
3-D shear wave velocity model of the lithosphere below the Sardinia-Corsica continental block based on Rayleigh-wave phase velocities
}

\author{
Fabrizio Magrini ${ }^{\oplus},{ }^{1}$ Giovanni Diaferia ${ }^{\oplus},{ }_{1}^{1}$ Islam Fadel ${ }^{\oplus},{ }^{2}$ Fabio Cammarano, ${ }^{1}$ Mark van \\ der Meijde ${ }^{2}$ and Lapo Boschi ${ }^{\oplus 3}$ \\ ${ }^{1}$ Department of Geological Science, Università degli Studi Roma Tre, 00146 Roma, Italy.E-mail: fabrizio.magrini@uniroma3.it \\ ${ }^{2}$ Faculty of Geo-Information Science and Earth Observation (ITC), University of Twente, 7500 AE Enschede, The Netherlands \\ ${ }^{3}$ Dipartimento di Geoscienze, Università degli Studi di Padova, 35131 Padova, Italy
}

Accepted 2019 December 29. Received 2019 November 29; in original form 2019 July 18

\begin{abstract}
SUMMAR Y
Rayleigh-wave dispersion curves from both ambient noise and teleseismic events allow us to provide the first high-resolution 3-D shear wave velocity $\left(V_{S}\right)$ model of the crust and upper mantle below the Sardinia-Corsica microplate, an important continental block for understanding the evolution of the central-western Mediterranean. For a wide range of periods (from 3 to $\sim 30 \mathrm{~s}$ ), the phase velocities of the study area are systematically higher than those measured within the Italian peninsula, in agreement with a colder geotherm. Relative and absolute variations in the $V_{S}$ allow us to detect a very heterogeneous upper crust down to $8 \mathrm{~km}$, as opposed to a relatively homogeneous middle and lower crust. The isosurface at $4.1 \mathrm{~km}$ $\mathrm{s}^{-1}$ is consistent with a rather flat Moho at a depth of $28.0 \pm 1.8 \mathrm{~km}(2 \sigma)$. The lithospheric mantle is relatively cold, and we constrain the thermal lithosphere-asthenosphere boundary at $\sim 100 \mathrm{~km}$. We find our estimate consistent with a continental geotherm based on a surface heat flow of $60 \mathrm{~mW} \mathrm{~m}{ }^{-2}$. Our results suggest that most of the lithosphere endured the complex history of deformation experienced by the study area and imply, in general, that deep tectonic processes do not easily destabilize the deeper portion of the continental lithosphere, despite leaving a clear surface signature.
\end{abstract}

Key words: Composition and structure of the continental crust; Crustal imaging; Seismic noise; Seismic tomography.

\section{INTRODUCTION}

The Sardinia-Corsica microplate is located in the middle of the central-western Mediterranean and represents a crucial continental block for understanding the evolution of both the Liguro-Provençal and the Tyrrhenian basins (Fig. 1). From a geological point of view, this block represents a portion of the southern European palaeomargin from which it has been separated for around $30 \mathrm{Ma}$, due to the opening of the Liguro-Provençal basin (e.g. Speranza et al. 2002; Faccenna et al. 2014). According to several studies (e.g. Alvarez 1972; Faccenna et al. 2002), this process was the consequence of the trench retreat that is currently active below Calabria and was accompanied by extensive subduction-related volcanism, which occurred throughout the Miocene with a peak around $20 \mathrm{Ma}$ (Lustrino et al. 2013). The fast opening of the backarc Tyrrhenian basin in the last $6 \mathrm{Ma}$, probably associated with the tearing and rapid trench retreat of the Apennine slab (e.g. Wortel \& Spakman 2000), left the
Sardinia-Corsica block behind. Between $\sim 4.8$ and $\sim 0.1$ Ma, Sardinia also experienced a minor episode of anoregenic volcanism together with a new extensional phase (Lustrino et al. 2013), perhaps associated with a large-scale NW-SE rifting extending up to the Sicily channel (e.g. Corti et al. 2006); this caused the formation of the Campidano graben and the deposition of plio-pleistocenic sediments (Fig. 1). The Variscan (Palaeozoic) units are mostly plutonic (granites/granitoids) and high-grade metamorphic rocks, and the Alpine metamorphic units constitute the so-called Alpine-Corsica (i.e. the northeastern portion of the island; Carmignani et al. 2016; Malusá et al. 2016). The western portion of Sardinia is characterized mostly by the presence of volcanic rocks that are separated from the Varisian basement by the so-called Sardinian Trough, an $\mathrm{N}-\mathrm{S}$ oriented graben.

The Sardinia-Corsica continental block therefore holds petrological signatures of several tectonic processes, but its role in the complex dynamics occurring in the central Mediterranean is not 


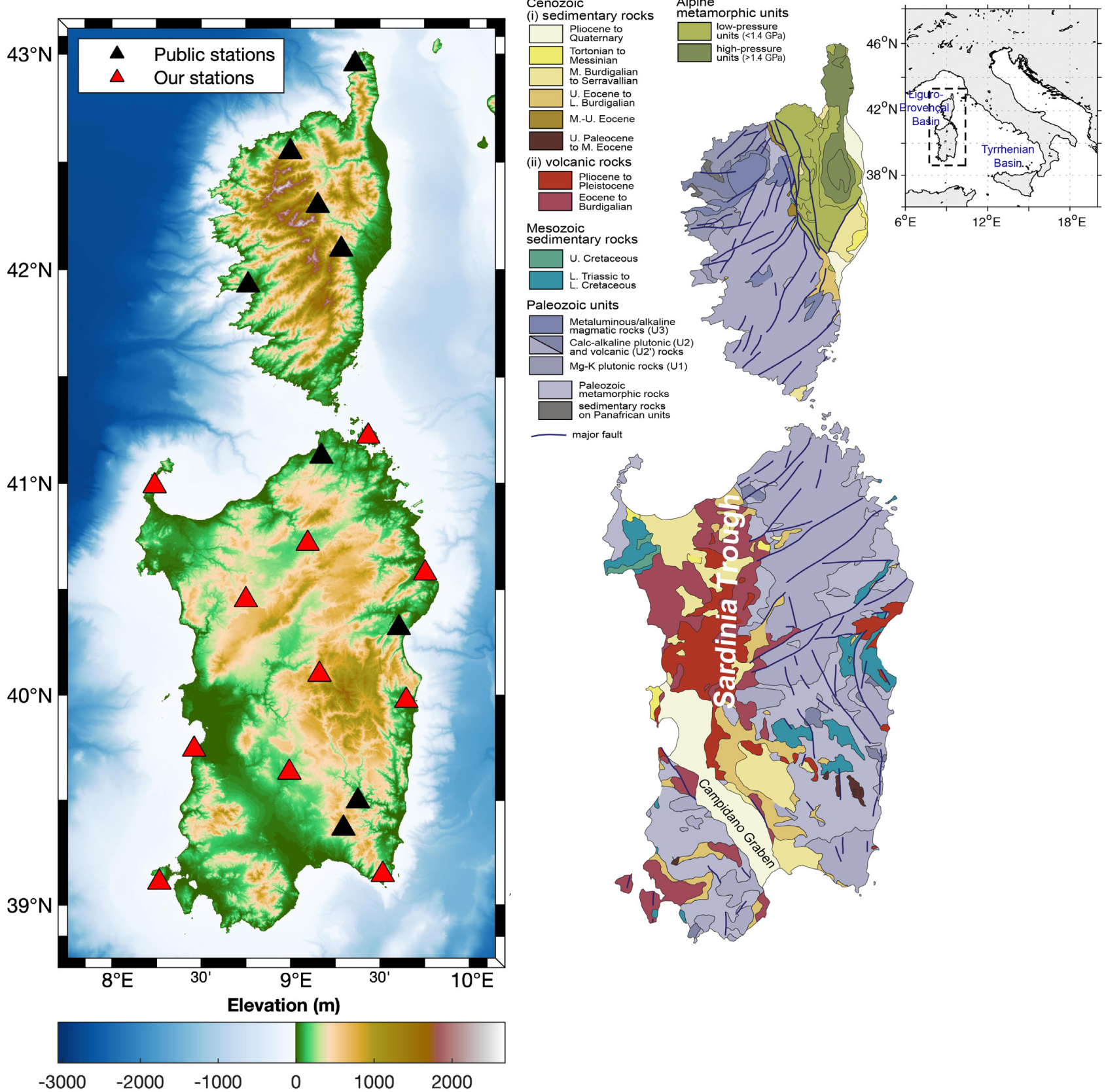

Figure 1. Left: locations of the seismic stations in the Sardinia and Corsica islands used for this study. In black are the public stations (from INGV and RESIF) and in red are our temporary stations installed for this study. Right: geological map of Sardinia, modified from Malusá et al. (2016).

yet fully understood (e.g. Oggiano et al. 2009). In fact, although the central-western Mediterranean has been extensively studied for many decades (e.g. Panza et al. 2007; Jolivet et al. 2009; Lustrino et al. 2011; Carminati et al. 2012; Faccenna et al. 2014), the scarcity of seismic stations on the Sardinian territory has until now hindered the acquisition of seismic images of the study area at lithospheric scale. The recent installation of the UT LiSard (Lithosphere of Sardinia) seismic array, together with the public data available from Istituto Nazionale di Geofisica e Vulcanologia (INGV) and Reseau sismologique et géodésique français (RESIF), provides us with continuous waveforms recorded at 20 receivers scattered across Sardinia and Corsica (Fig. 1), and enables us to investigate the Earth structure beneath this continental block.
In order to characterize the lithosphere of the study area we use Rayleigh-wave phase-velocity measurements. Phase velocities of the fundamental Rayleigh-wave mode have proved to be an essential seismological tool for studying the Earth's lithosphere and the sublithospheric mantle, allowing discrimination between provinces characterized by different temperatures and/or compositions on the basis of their different wave speeds (e.g. Christensen \& Mooney 1995; Shapiro \& Ritzwoller 2004). In recent years, an increasing interest in refining and automating the procedures for estimating the surface-wave velocities has brought to a rapid development of the techniques for the measurement of interstation group and phase velocities of both earthquake-based (EQ; e.g. Lin et al. 2009; Yang et al. 2011; Jin \& Gaherty 2015; Soomro et al. 2016) and ambient 
noise (AN; e.g. Shapiro et al. 2005; Bensen et al. 2007; Ekström et al. 2009; Kästle et al. 2016) fundamental-mode surface waves. Here we make use of both EQ and AN: these two types of seismic signals contain complementary information, and their combination results in a data set that is sensitive to a broad depth range (e.g. Meier et al. 2004; Ritzwoller et al. 2011; Köhler et al. 2012; Zhou et al. 2012; Kästle et al. 2016). Whereas the earthquake-generated signals are dominated by relatively low frequencies - and therefore provide constraints on deeper structures - passive seismic interferometry brings information on the shallow part of the Earth.

For the majority of the stations, more than $2 \mathrm{yr}$ of continuous seismograms (from June 2016 to September 2018) are available. This ensures that a relatively large number of AN sources at different azimuths contribute to the waveforms (which is essential for the application of seismic interferometry; e.g. Boschi \& Weemstra 2015) and that a sufficiently large number of earthquakes can be exploited for this study. In the following section, we describe the two complementary methods used for retrieving dispersion measurements at different periods, and therefore for generating the phase-velocity maps of the study area. The data analysis and the inversion results can be found in Sections 3 and 4, respectively. In Section 5, we present the discussion of the final model and the interpretation.

\section{METHODS}

\subsection{Ambient noise}

We retrieved the Rayleigh-wave dispersion curves from the vertical component of recorded noise using an automated algorithm that measures the phase velocities for a given station pair by crosscorrelation in frequency domain and stacking of noise records (Kästle et al. 2016). This algorithm, based on the ideas of Aki (1957) and Ekström et al. (2009), relies on the fact that the spectrum of the two-stations cross-correlation of seismic AN approximately coincides with a 0 -order Bessel function of the first kind (Boschi et al. 2013). This circumstance allows us to extract the phase velocities at the zero-crossings, as fully explained in Kästle et al. (2016).

The first stage of data processing consisted of preparing the waveform data from each station individually. To this purpose, the seismograms were pre-filtered using a bandpass filter from 0.005 to $0.75 \mathrm{~Hz}$, with instrument response deconvolved to displacement, de-meaned, de-trended and downsampled to $2 \mathrm{~Hz}$. We zero-padded wherever gaps appeared in the signal, in order to obtain continuous time-series. We cross-correlated the spectra from every combination of station pairs by selecting the longest common time window available between the two stations. Specifically, each cross-correlation was performed by cutting the data into shorter overlapping time intervals and ensemble averaging the cross-spectra calculated in each of them; the overlap parameter (50 per cent; see Seats et al. 2012 , for a more detailed discussion on the topic) and the $\Delta t$ intervals $(900 \mathrm{~s})$ have been chosen on the basis of the relatively short interstation distances that characterize the array $(\sim 140 \mathrm{~km}$ on average). Spectral whitening was applied to data before multiplication in frequency domain in order to mitigate the effect of possible ballistic signals (i.e. large earthquakes; Boschi et al. 2013) and to reduce the influence from monochromatic sources (e.g. Bensen et al. 2007).

The above procedure allowed us to retrieve average interstation dispersion measurements for periods ranging from 2.5 up to $20 \mathrm{~s}$.
In order to generate $\mathrm{AN}$ phase-velocity maps at different periods (Fig. 3), we adopted a linearized inversion algorithm based on the ray theory. This algorithm is fully described in Boschi \& Dziewonski (1999) and has been modified by Lu et al. (2018), who implemented an adaptive spatial parametrization based on the path density. We meshed the region of interest with $1.6^{\circ}$ cells, and the areas with more than 15 paths per cell were iteratively discretized halving the size of the mesh, up to a maximum of four times. The final grid we obtained has cells of $0.2^{\circ}$ across most of the study area at all periods. Based on an L-curve analysis, we chose to apply a norm damping equal to 0.8 for all periods, in order to compromise the trade-off between data fitting and regularization (Hansen 2001). This value returns phase-velocity maps that are relatively smooth (Fig. 3), and they will be discussed in the following section.

\subsection{Helmholtz tomography}

We retrieved the Rayleigh phase velocities from teleseismic surface waves using an open source, automated algorithm that measures the frequency-dependent interstation phase delays between all possible nearby stations by cross-correlation in time domain (Jin \& Gaherty 2015). Using the Eikonal equation, the phase variations are first inverted for spatial variations in apparent phase velocities; the Helmholtz equation then allows us to correct the bias between apparent phase velocity and structural phase velocity by accounting for the surface wave amplitudes measured at the individual stations (for more details, see Jin \& Gaherty 2015). Importantly, this algorithm exploits a multichannel approach, without assuming surface wave propagation along the great-circle path and therefore does not restrict the number of usable measurements.

We selected shallow $(<50 \mathrm{~km})$ events with magnitude 6.0 or larger, limiting the epicentral distances to a range between $20^{\circ}$ and $160^{\circ}$ from the center of the array $\left(\sim 40^{\circ} \mathrm{N}, 9^{\circ} \mathrm{E}\right)$, resulting in 175 exploitable teleseismic earthquakes (Fig. 2). The preparation of the data consisted of removing the instrument response, decimating to $1 \mathrm{~Hz}$ after low-pass filtering to prevent aliasing, and, for each event, slicing the waveform data into $7200 \mathrm{~s}$ time intervals beginning at the origin time of the respective event. In order to obtain the phasevelocity maps we chose a grid size of $0.25^{\circ}$, and we tested several different combinations of the quality control parameters available in the algorithm, relying on the operating manual provided by Jin \& Gaherty (2015) and on previous applications of the method (e.g. Martin-Short et al. 2018).

The above procedure allowed us to retrieve phase-velocity maps (together with their uncertainties) for periods ranging from 20 to $80 \mathrm{~s}$ (Fig. 4).

\section{DATA ANALYSIS}

\subsection{Phase velocities}

We show in Figs 3 and 4 the phase-velocity maps we obtained using AN and EQ, respectively. The robustness and the uncertainties of the maps are discussed in detail in Section 3.2. It is worth pointing out here, however, that their resolution is maximum in the central part of the study area, where the density of interstation paths is maximum (Fig. 5), as also suggested by the standard deviations of the EQ phase-velocity maps (Fig. 4, bottom panel). At the periods investigated by AN, the phase-velocity maps show an increasing velocity eastwards (Fig. 3) that strongly resembles the subdivision between Palaeozoic units and more recent ones, as illustrated in 

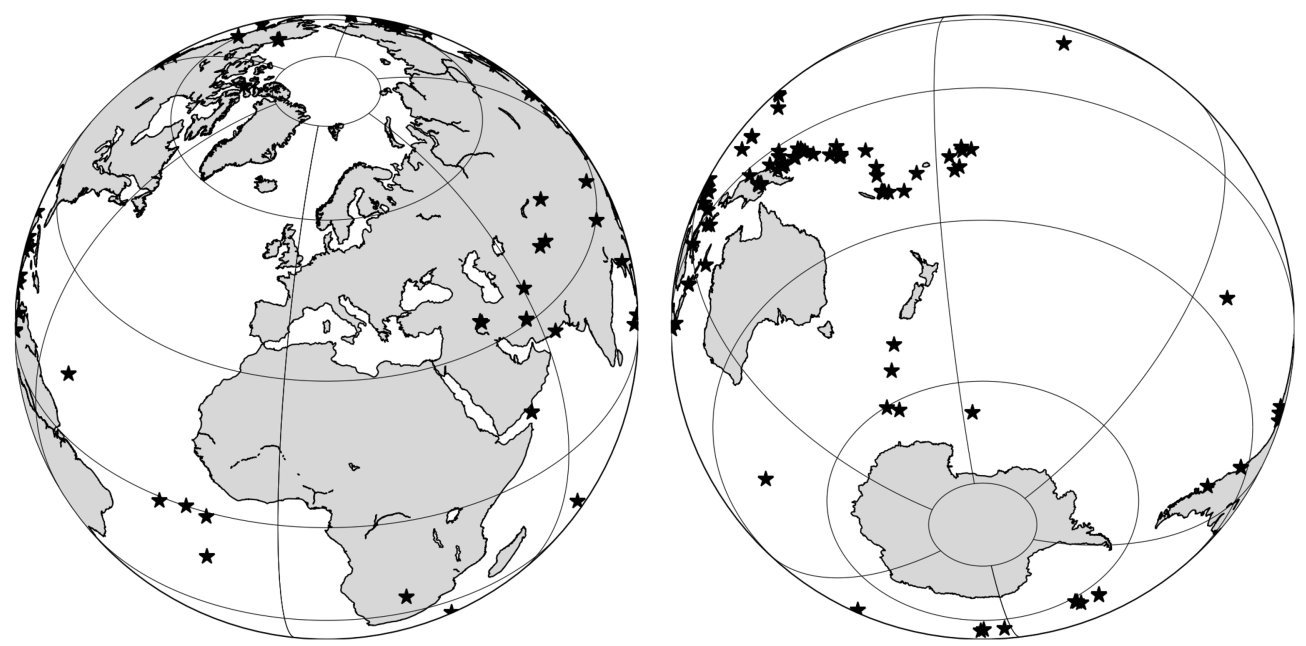

Figure 2. Map of teleseismic events (stars) used in this study.

Fig. 1. This pattern is smeared out with increasing periods and appears to be completely vanished at $\sim 18 \mathrm{~s}$. At periods longer than $20 \mathrm{~s}$ (Fig. 4), instead, the study area is characterized by a different seismic structure. This is particularly visible at periods longer than $30 \mathrm{~s}$, where Sardinia is defined by relatively high phase velocities compared to the Corsica island. These features are interpretable in terms of temperature and composition, and will be further discussed in Section 5.

Fig. 6 shows the velocity profiles we used for inverting the phase velocities to shear wave velocities. These are obtained by interpolating the phase-velocity maps from both $\mathrm{AN}$ and EQ on a regular grid defined by longitude and latitude steps of $0.17^{\circ}$ and $0.15^{\circ}$, respectively. At the period of $20 \mathrm{~s}$, where both AN and EQ measurements are available, the mean values are taken, and each profile is then smoothed by fitting a ninth-order polynomial to the data. This is justified by the fact that the averaging properties of the surface wave dispersion with depth make any jump in the dispersion curves unrealistic (Kästle et al. 2018). Compared to the Italian peninsula (Molinari et al. 2015), on average Sardinia and Corsica are characterized by higher phase velocities (Fig. 6), with substantially higher median values in a wide range of periods (from $\sim 5$ up to $\sim 30 \mathrm{~s}$ ). It is worth noting that the $1-\mathrm{D}$ profiles obtained from the phasevelocity maps are characterized by a relatively smooth continuity between the phase velocities we retrieved from AN and EQ. Specifically, in order to quantify their consistency, the period of $20 \mathrm{~s}$ turns out to be crucial for this study, representing the only connecting link between the two techniques. In this regard, at $20 \mathrm{~s}$ the phasevelocity maps are in overall good agreement, with a mean difference in absolute velocity of $0.067 \mathrm{~km} \mathrm{~s}^{-1}$ and a standard deviation of $0.066 \mathrm{~km} \mathrm{~s}^{-1}$.

\subsection{Uncertainty evaluation of the phase-velocity maps}

Mapping the uncertainties on the EQ measurements (Fig. 4) is generally not problematic because for every pair of stations many measurements are available, and a statistical analysis on the agreement of the results can be carried out easily. However, the same does not apply to AN, where the cross-spectrum calculated from continuous waveforms is required. This circumstance hinders the collection of more than one dispersion curve for a given pair of receivers and, therefore, does not allow a direct estimation of the uncertainty of the measurements.
For this reason, in order to estimate the uncertainty relative to the AN-based measurements we performed two different analyses. The first one is based on a bootstrap method and must be considered to be indicative of the robustness of the technique: for every pair of stations we calculate 150 dispersion curves, randomly zero-padding $5 \mathrm{~d}$ a month before cross-correlating. For every combination of stations it is then possible to evaluate the probability distribution of the measurements. In this regard, the technique proved to be quite stable, with average frequency-dependent standard deviations systematically below $0.01 \mathrm{~km} \mathrm{~s}^{-1}$. The second approach we used is based on the method of the triplets, explained by Lin et al. (2008) in detail. For each triplet of stations approximately lying on the same great-circle path (we allowed a maximum deviation of $15^{\circ}$ ), the phase-velocity measurement from the most distant pair of stations is compared to the remaining two, weighting the velocities according to the interstation distances. Due to the relatively small number of stations constituting our array, the number of usable triplets for carrying out this analysis was obviously restricted. Nonetheless, at each frequency we were able to extract measurements of the bias affecting the AN dispersion curves that closely approximate normal distributions, whose mean and standard deviation give indication on the uncertainty, as shown in Fig. 3.

It must be noted that the measured uncertainty on the AN dispersion curves does not provide any spatial information (i.e. it is not mappable) and turns out to be substantially lower than the one affecting our EQ data (Fig. 4). Indeed, especially in the areas where the density of the interstation paths is lower (i.e. at the boundaries of the maps and in the Corsica island; Fig. 5), at periods longer than $40 \mathrm{~s}$ we observe standard deviations as high as the 10 per cent of the average phase velocity at the considered period. The propagation of the uncertainties must be taken into account when inverting the phase-velocity maps for obtaining a shear wave velocity model and will be further discussed in Section 4.2.

\section{INVERSION TO SHEAR WAVE VELOCITIES}

\subsection{Inversion method}

The 1-D phase-velocity profiles (Fig. 6) are inverted individually for the 1-D shear-velocity $\left(V_{S}\right)$ structure (Fig. 7). The generated depth 

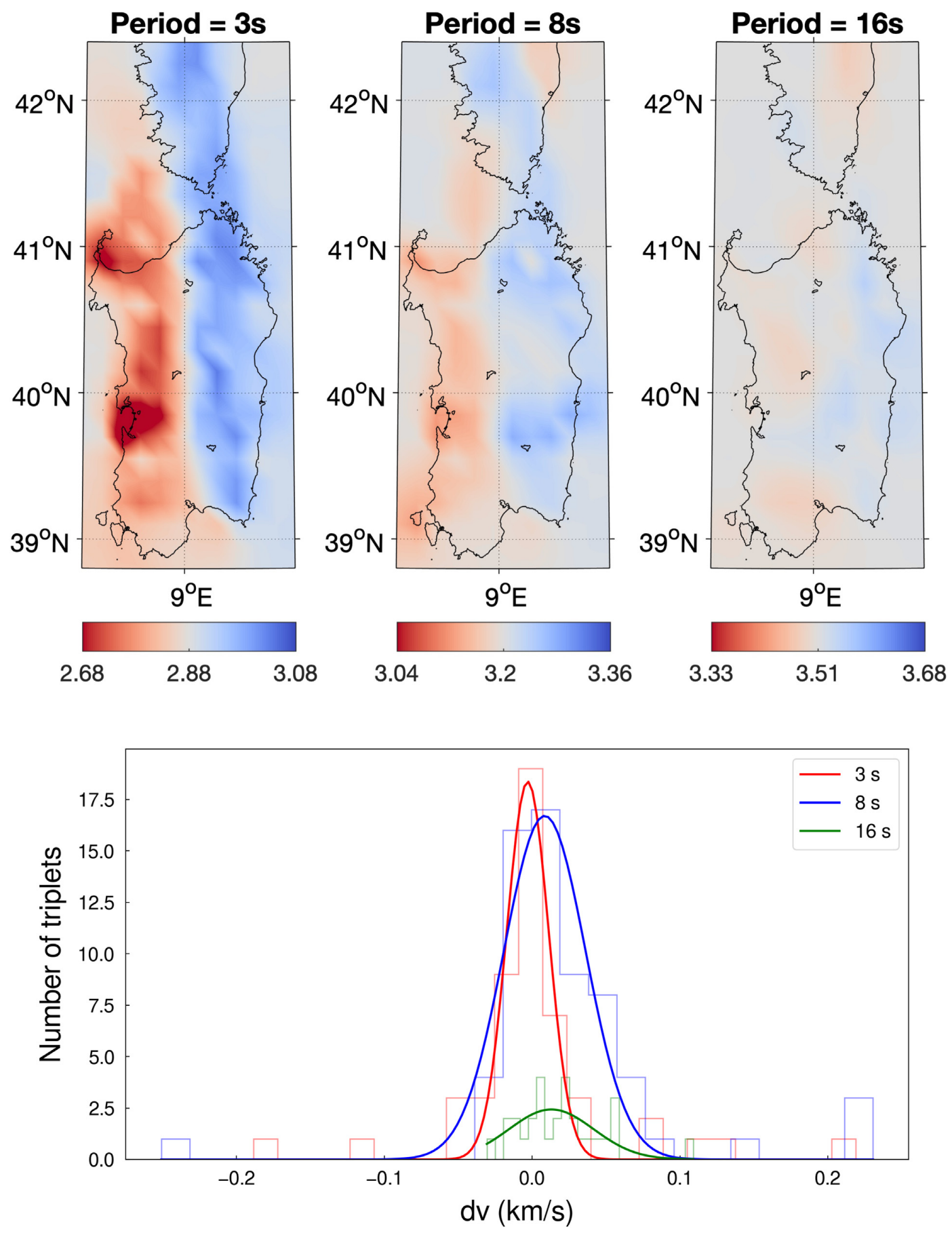

Figure 3. Upper panel: AN phase-velocity maps at different periods $(3,8$ and $16 \mathrm{~s})$. The colour scale (in $\mathrm{km} \mathrm{s}^{-1}$ ) is set to \pm 7 per cent of the mean value at the period of $3 \mathrm{~s}$, and to \pm 5 per cent at the remaining ones. Lower panel: uncertainties on the AN data at the same periods, calculated with the method of the triplets (see Section 3.2). Red (3 s): $\mu=-0.003 \mathrm{~km} \mathrm{~s}^{-1}, \sigma=0.014 \mathrm{~km} \mathrm{~s}^{-1}$. Blue $(8 \mathrm{~s}): \mu=0.008 \mathrm{~km} \mathrm{~s}^{-1}, \sigma=0.028 \mathrm{~km} \mathrm{~s}^{-1}$. Green $(16 \mathrm{~s}): \mu=0.013 \mathrm{~km}$ $\mathrm{s}^{-1}, \sigma=0.029 \mathrm{~km} \mathrm{~s}^{-1}$.

profiles are then combined to create a 3-D shear-velocity model. The inversion is performed by means of a damped iterative linearized inversion (Greve et al. 2014). A starting model is calculated from the average dispersion curve of the study area and, for each location, it is iteratively perturbed trying to minimize a misfit function that depends on (1) the misfit between the calculated and the observed phase-velocity dispersion curve, (2) the vertical smoothness of the model and (3) the difference between the background and the inverted model. We discretized the model using layers of progressively increasing thickness with depth, without including any constraints regarding the Moho: layers $2 \mathrm{~km}$ thick in the first $10 \mathrm{~km}, 5 \mathrm{~km}$ thick from 10 to $50 \mathrm{~km}, 10 \mathrm{~km}$ thick from 50 to $100 \mathrm{~km}$, and $20 \mathrm{~km}$ thick between 100 and $400 \mathrm{~km}$. The inversion was carried out for structures as deep as $400 \mathrm{~km}$ in order to avoid leakage from (otherwise fixed) deeper structures into the shallow structure (Greve et al. 2014). Following Ma \& Clayton (2014), we tested that the inversion results were independent from the chosen starting model. 

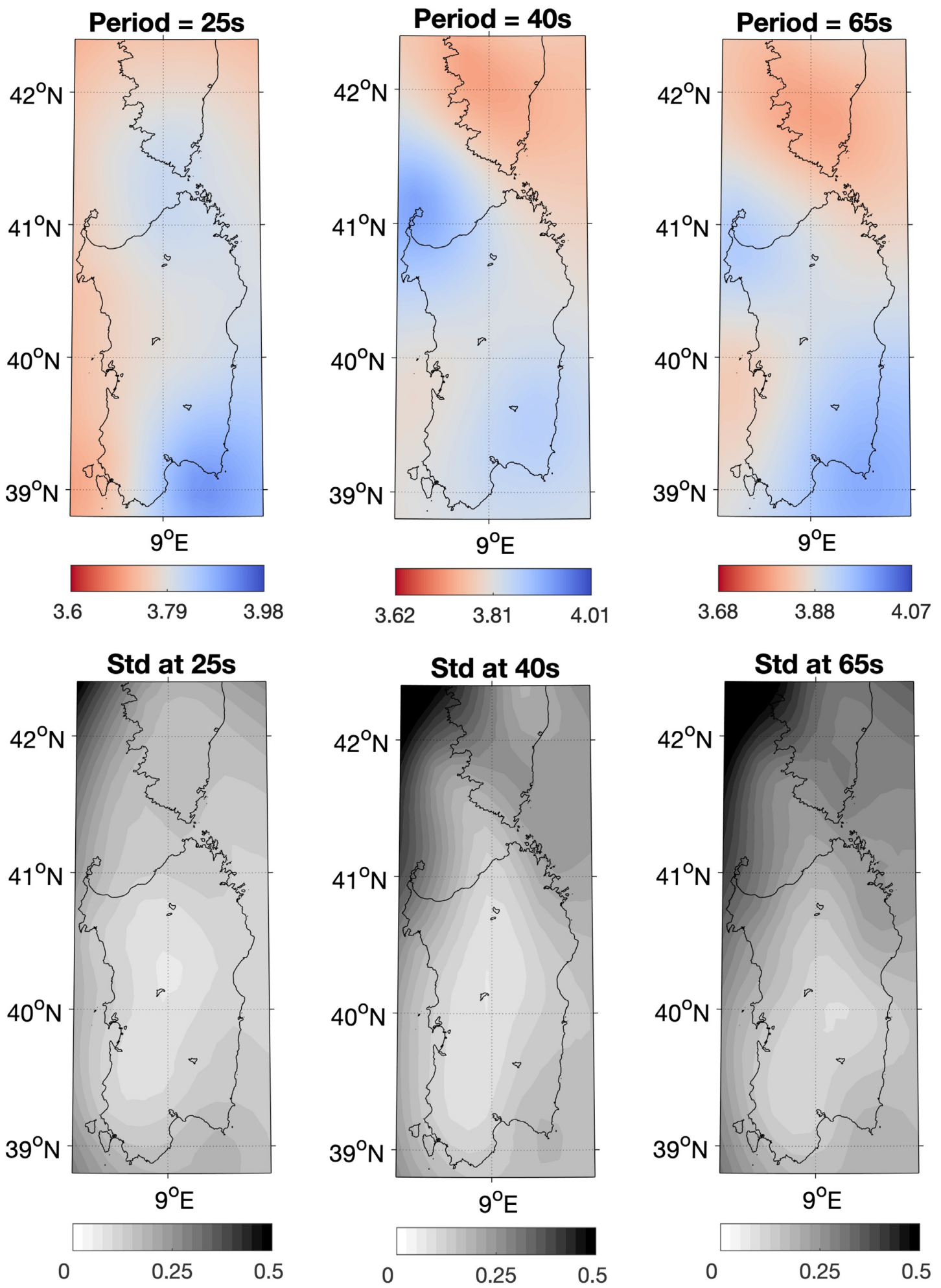

Figure 4. EQ phase-velocity maps at different periods (25, 40 and $65 \mathrm{~s}$ - upper panel) and their respective standard deviations (lower panel). For the phasevelocity maps, at each period the colour scale (in $\mathrm{km} \mathrm{s}^{-1}$ ) is set to \pm 5 per cent of the mean value. The colour scale of the standard deviations, instead, is fixed between 0 and $0.5 \mathrm{~km} \mathrm{~s}^{-1}$.

\subsection{Uncertainty evaluation of the inverted model}

As already mentioned in Section 3.2, the earthquake-based data are affected by a higher uncertainty in comparison to the AN ones, especially at relatively long periods. Therefore, we considered to be worth evaluating how these uncertainties propagate in the inverted model. In this regard, we performed a test based on a Monte Carlo sampling of the inverted model, for convenience parametrized in six layers whose sensitivity kernels are calculated for each period. The test is run for a layer at a time by iteratively perturbing the layer's shear wave velocity. The perturbation is carried out by randomly 


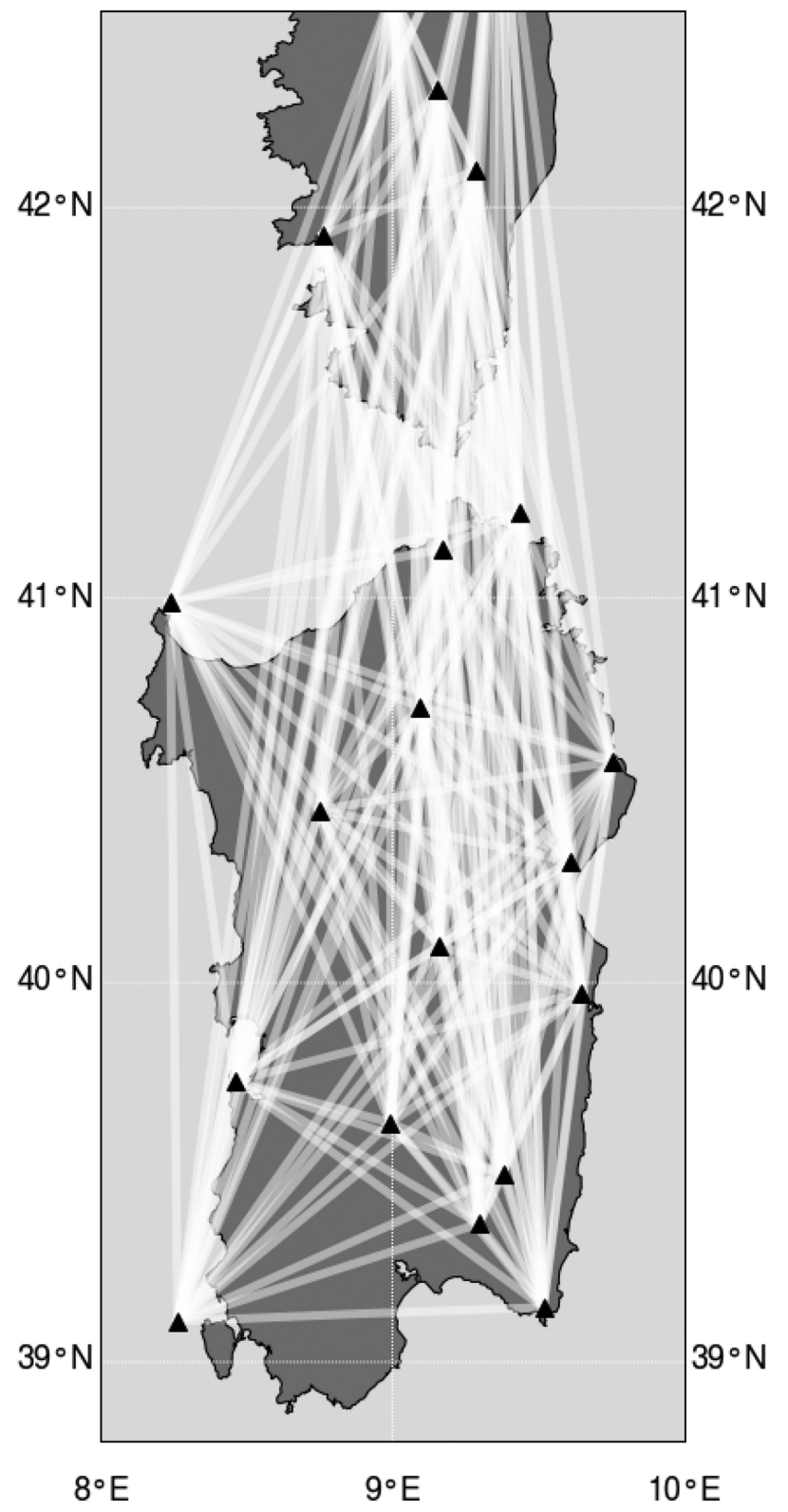

Figure 5. Interstation ray paths. The black triangles represent the seismic stations available for this study.

sampling from a wide Gaussian distribution of $\sigma=0.5 \mathrm{~km} \mathrm{~s}^{-1}$. The misfit between the forward response of the perturbed model and the observed dispersion curve is then calculated, weighted by the sensitivity kernel of the selected layer, and divided by the data uncertainties. Using the sensitivity kernel of the layer as weighting parameter allows us to isolate the contribution of such layer to the data misfit. In vectorial form, the misfit is

misfit $=\left(\mathbf{d}_{\mathbf{o b s}}-\mathbf{d}_{\mathbf{m}}\right)^{T} \mathbf{K} \mathbf{C}^{-1}\left(\mathbf{d}_{\mathbf{o b s}}-\mathbf{d}_{\mathbf{m}}\right)$,

where $\mathbf{d}_{\mathbf{o b s}}$ and $\mathbf{d}_{\mathbf{m}}$ are the observed and forward dispersion curves, $\mathbf{K}$ is the diagonal matrix of the sensitivity kernel, $\mathbf{C}$ is the diagonal matrix of the uncertainties of observed data. Considering the models with the best 10 per cent misfit, these show an average deviation of $\sim 1.2$ per cent. We therefore conclude that the inverted model can be considered rather robust in light of the data uncertainties.

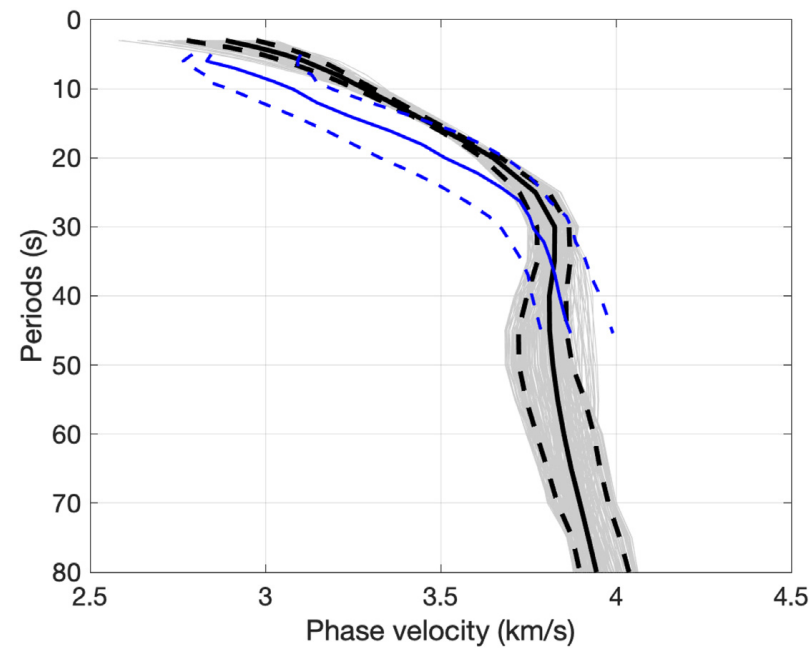

Figure 6. Median (continuous lines), 10th and 90th percentiles (dashed lines) of the Rayleigh-wave phase velocities as function of period of the Sardinia-Corsica continental block (black) and of the Italian peninsula (blue, obtained by Molinari et al. 2015). The phase-velocity profiles of the study area are smoothed by fitting a ninth-order polynomial to the data.

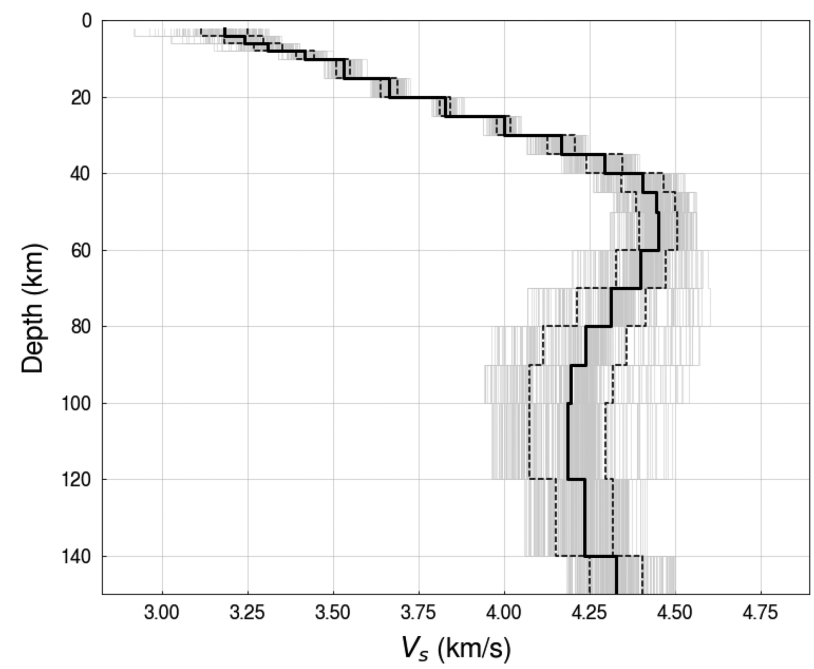

Figure 7. The $V_{S}$ depth profiles we retrieved from the inversion (gray). The mean value (bold line) and the standard deviation (dashed lines) are shown in black.

\subsection{Horizontal and vertical resolution of the inverted model}

Before presenting the interpretation of the results, we want to emphasize that the resolution of the final model directly depends on the resolution of the phase-velocity maps. Therefore, the horizontal and the vertical information brought by the final model must be treated differently. Following Yoshizawa \& Kennett (2002), we consider the horizontal resolution of the phase-velocity maps to be regulated by $\lambda / 3$, where $\lambda$ is the wavelength. Since $\lambda=v T$ (e.g. Cassidy et al. 2002), the horizontal resolution of the seismic structure linearly decreases with the investigated period $T$. In other words, increasing the period, the measurement will be representative of a phase velocity averaged over increasingly larger volumes, and therefore will bring less and less information about the lateral variations. A sensitivitykernel analysis shows that the maximum sensitivity for a period of $40 \mathrm{~s}$ (at which the horizontal resolution is $\sim 50 \mathrm{~km}$ ) is located at 
$\sim 70 \mathrm{~km}$ depth, and therefore we will not consider any depth greater than $70 \mathrm{~km}$ in the discussion of the lateral variations of the model (Fig. 8). On the other hand, we argue that the meaningfulness of the mean 1-D $V_{S}$ profile extends well below such depth. Since the period of $80 \mathrm{~s}$ (the maximum period we were able to investigate) characterized by a peak of sensitivity at $\sim 125 \mathrm{~km}$ that progressively decreases with depth, in what follows we will discuss some of the patterns that can be observed in the 1-D $V_{S}$ profiles (Fig. 7) up to depths of $150 \mathrm{~km}$.

Furthermore, it should be noted that the shear-velocity maps presented in Fig. 8 are blanked at 35, 50, and $70 \mathrm{~km}$ where the standard deviations of the phase-velocity maps at 30 s exceed $0.2 \mathrm{~km}$ $\mathrm{s}^{-1}$. This is motivated by the fact that, at such depths, the shear wave velocity model is constrained only by the EQ phase velocities, affected by relatively high uncertainties on the areas characterized by worse seismic coverage. Nonetheless, this conservative choice allows us to discuss what should be considered the most robust features of the final model.

\section{DISCUSSION}

\subsection{Lateral variations of the shear wave velocity model}

The $V_{S}$ maps in Fig. 8 show some of the patterns we already mentioned in Section 3.1. The seismic structure of the shallow part of the study area closely resembles its surface geology: if the lithologies are subdivided in Palaeozoic units and more recent ones, it is possible to follow an $\mathrm{N}-\mathrm{S}$ oriented line (along the $9^{\circ} \mathrm{E}$ meridian) that clearly separates them (Fig. 1). Whereas the Variscan basement outcrops especially in the east of Sardinia and is fairly widespread in Corsica, the west of Sardinia is dominated by the presence of Cenozoic sedimentary and volcanic rocks. In our model, from the surface down to $\sim 8 \mathrm{~km}$, we observe a very similar geometry: the Corsica island and the east of Sardinia are characterized by higher velocities than the western part of Sardinia. Notably, the region that is characterized by the lowest $V_{S}$ (Fig. 8 , slice at $5 \mathrm{~km}$ ) is located exactly in correspondence with the plio-pleistocenic sediments that cover the Campidano graben, and the northeastern part of Corsica (Alpine Corsica) shows lower velocities than the plutonic region characterizing central Corsica (Fig. 1). A seismic refraction survey by Egger et al. (1988) showed no evidence of strong lateral variations in terms of compressional wave speed within the crust of Sardinia and Corsica. This would imply that the strong lateral $V_{S}$ heterogeneity we observe in the shallow part of the study area be mainly driven by compositional differences between the granitoids of the Variscan basement and the porous/wet volcanosedimentary cover (e.g. Christensen 1996; Behn \& Kelemen 2003).

The strong lateral variations in velocity observed within the upper crust quickly disappear at greater depths. Indeed, between $\sim 8$ and $\sim 30 \mathrm{~km}$ the study area shows a rather homogeneous seismic structure (Fig. 8). We consider this result to be relevant especially in light of the recent volcanism that affected the Sardinia island (e.g. Lustrino et al. 2013), whose evidence is particularly visible in its western part. In this regard, the seismic structure of the middle and of the lower crust does not suggest any possible source of the Miocene volcanism.

Nonetheless, deeper lithospheric slices (>35 km, Fig. 8) suggest the presence of a laterally non-homogeneous structure, with high velocities in the northern and in the southern part of Sardinia, which is accentuated at increasing depths. We consider this change from a homogeneous to a more heterogeneous seismic structure to be representative of the transition from the lower crust to the lithospheric mantle. This consideration is supported by previous studies based on receiver functions (e.g. van der Meijde et al. 2003; Di Stefano et al. 2011) and seismic refraction surveys (Egger et al. 1988), which locate the Moho in the study area at a depth of $\sim 30 \mathrm{~km}$. Using an isosurface at $V_{S}=4.1 \mathrm{~km} \mathrm{~s}^{-1}$ as a proxy for Moho depth, we obtain a rather flat surface, characterized by a mean depth of $28.0 \mathrm{~km}$ and a standard deviation of $0.9 \mathrm{~km}$. It should be noted that the choice of an isosurface for constraining the Moho depth from a $V_{S}$ model is inevitably arbitrary. However, a value of $4.1 \mathrm{~km} \mathrm{~s}^{-1}$, besides resulting in Moho depths in agreement with the aforementioned studies, returns the depth values that best fit those estimated at the LiSard stations on the basis of independent, yet unpublished receiver function results.

The presence of a heterogeneous seismic structure in the upper portion of the Sardinian lithospheric mantle supports the idea of lower crustal lithologies present at upper-mantle depths, suggested, for example, by Lustrino et al. (2013). According to the same authors, this would be consistent with a delamination process occurred when the Sardinian crust was hotter (as proven by the past magmatism) and more unstable due to the eastward mantle flow that led to the opening of the Liguro-Provençal and the Tyrrhenian basins, and can explain the mantle signature that has been observed in the fluids of the geothermal system in the central-western Sardinia (e.g. Paternoster et al. 2017). We should point out, however, that while intriguing and geologically sounding, the occurrence of such a process cannot be fully confirmed based on our study only; more in-depth, multi-disciplinary studies including, for example, gravity, petrophysics and seismic wave attenuation would be necessary for this purpose (e.g. Seber et al. 1996).

It is worth mentioning that the persistence of an heterogeneous mantle with depth cannot rule out completely the hypothesis of a plume-like body within the asthenosphere below the central-western Mediterranean, whose upwellings would feed the volcanic activity in part of the Italian peninsula and in the Tyrrhenian Sea. This model, supported by geochemical arguments, has been proposed in several studies (e.g. Gasperini et al. 2000, 2002; Lavecchia \& Creati 2006; Bell et al. 2013), and whether or not it is realistic, at the present time, is still strongly debated (see e.g. Lustrino et al. 2011, and citations therein). In this regard, a larger-scale geophysical study would certainly better clarify the origin of such a deep structure. However, the absolute velocities, which allow us to estimate the temperatures within the mantle of the study area, give us an indication of the unlikelihood of this idea and will be discussed in the following paragraphs.

\subsection{Depth profiles: the lithosphere-asthenosphere boundary (LAB)}

In Section 3.1, we already presented a comparison between the absolute phase-velocities we measured in the study area and the ones of the Italian peninsula (Fig. 6). The high absolute velocities below the crust indicate a relatively cold lithospheric mantle. Considering a normal mantle of pyrolitic composition, we estimate a temperature of $\sim 850{ }^{\circ} \mathrm{C}$ for the average $V_{S}$ of $4.4 \mathrm{~km} \mathrm{~s}^{-1}$ that we observe at $50 \mathrm{~km}$ (the conversion into temperature has been performed following Cammarano et al. 2003, 2011; Cammarano \& Guerri 2017, and relies on thermodynamic modelling and experimentally based elastic properties of mantle minerals). Therefore, we argue that the actual crustal temperatures in the study area are mostly controlled 

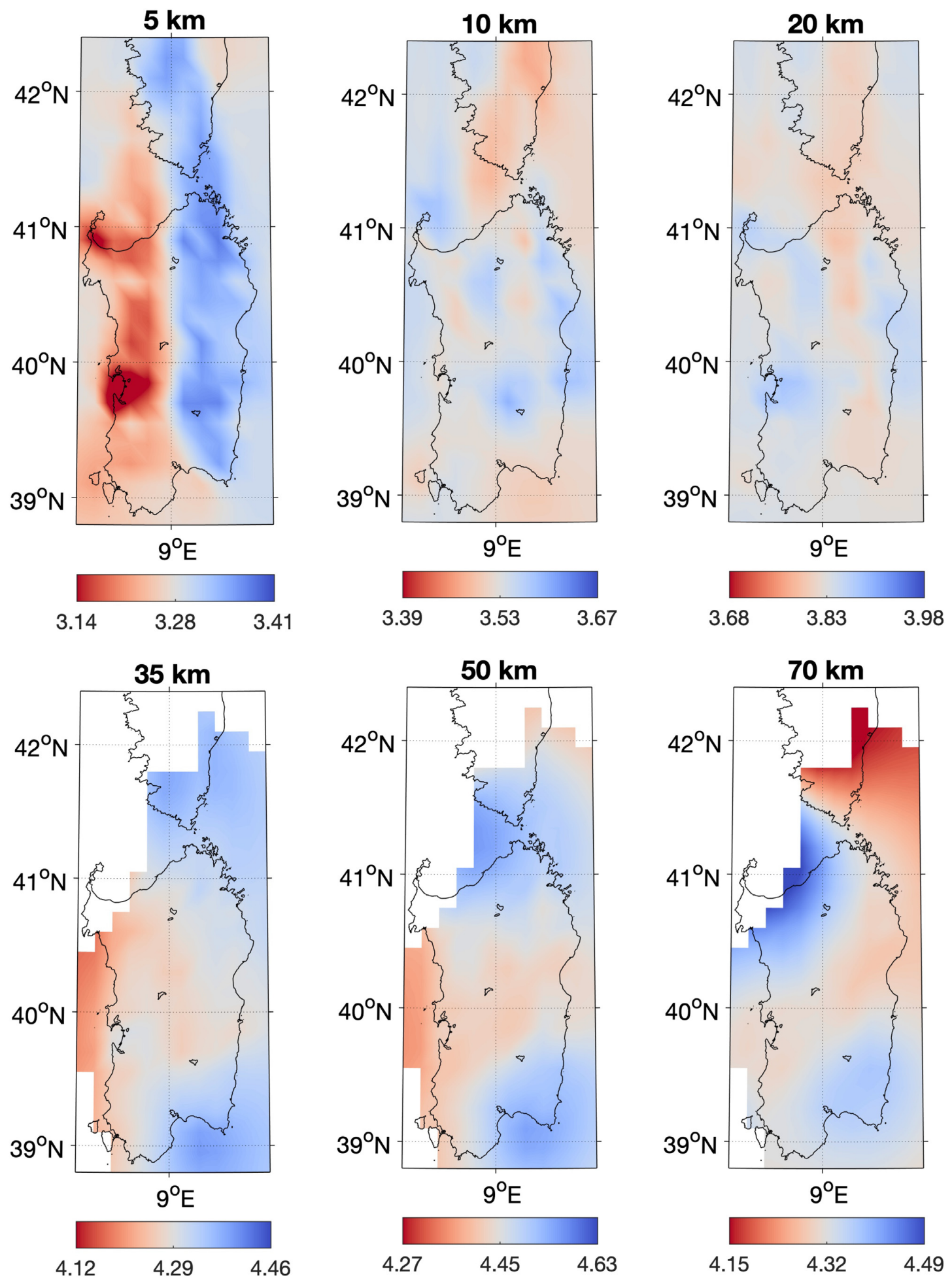

Figure 8. $V_{S}$ horizontal slices at different depths. At each depth, the colour scale (in $\mathrm{km} \mathrm{s}^{-1}$ ) is set to \pm 4 per cent of the mean value. Lithospheric slices that are only constrained by earthquake-based phase velocities are blanked where the standard deviations of the phase velocities at $30 \mathrm{~s}$ exceed $0.2 \mathrm{~km} \mathrm{~s}$.

by internal radiogenic heating within the crystalline basement. This interpretation is supported by the presence of thermal springs and high heat flow values (up to $180 \mathrm{~mW} \mathrm{~m}^{-2}$ ) in the northwest Sardinia, which have been proved to be related to radiogenic heating of Variscan granites and hydrothermal circulation (Cuccuru et al. 2015).
At depths greater than $50 \mathrm{~km}$, our model clearly shows a decrease in $V_{S}$ (Fig. 7). This trend is maintained at least until $100 \mathrm{~km}$, and we consider this depth to be representative of the base of the thermal lithosphere. It is worth noting that although this value differs from a previous estimate of the LAB depth made by Panza et al. (2007) for the study area, this discrepancy derives from the very definition 
of the LAB depth. Indeed, Panza et al. (2007) locate the LAB at a depth correspondent to the initial inversion of the $V_{S}$ gradient, and not at the end of the negative gradient. Regardless of the choice to be preferred, applying the same definition of LAB depth as Panza et al. (2007), our results turn out to be quite in good agreement ( $\sim 60-70 \mathrm{~km})$. In addition, our LAB estimate is also consistent with a steady-state continental geotherm based on an average heatflow of $60 \mathrm{~mW} \mathrm{~m}{ }^{-2}$, an approximate value calculated by Scrocca et al. (2003) for Sardinia. Finally, from the conversion of $V_{S}$ into temperature using a pyrolitic composition we obtain a value at the estimated $\mathrm{LAB}$ depth that is consistent with a potential temperature at surface of $1300{ }^{\circ} \mathrm{C}$. The careful reader may note that the average velocity we observe at the LAB depth $(\sim 100 \mathrm{~km})$ is similar to what we obtain at $\sim 40 \mathrm{~km}$ (Fig. 7); even though this result might appear ambiguous, the pressure effect makes the pyrolitic composition return a temperature that is in agreement with the expected mantle adiabat only at the LAB depth.

\subsection{Implications}

Our estimate of the LAB depth is consistent with a classical conductive continental geotherm. Surprisingly, this result would indicate that most of the continental lithosphere endured the complex history of deformation experienced by the study area, and has general implications on the role of deep tectonic processes in the erosion of the continental lithosphere. Whereas it is well known that old cratonic regions overlie cold and chemically depleted lithospheric mantles (which can reach depths greater than $200 \mathrm{~km}$; Gung et al. 2003), how continental lithosphere can survive for billions of years is still a matter of debate. As we mentioned in Section 1, the SardiniaCorsica microplate is an old continental block that underwent, in the last $30 \mathrm{Ma}$, several tectonic processes such as separation, drift, rotation from the Variscan European basement, subduction-related volcanism and, more recently, anorogenic volcanism. Considering the seismic structure, these are immediately evident in the upper crust, where the heterogeneity in temperature, porosity, presence of fluids, and composition manifests itself in the strong $V_{S}$ variations between the eastern and the western sides. On the other hand, our results show that the same tectonic processes did not disassemble the Sardinian lithospheric mantle as much as could be expected, at least at the degree of resolution that we have been able to achieve. For this reason, we consider the study area to be interesting for investigating the complex interaction between the lithospheric and the asthenospheric mantle at larger scale, and this will be the subject of a future study.

\section{CONCLUSIONS}

This study represents the first record of a high-resolution lithospheric imaging of the Sardinia-Corsica continental block, crucial for understanding the geodynamical processes that have contributed to the formation and evolution of the central Mediterranean. Rayleigh phase velocities calculated from both teleseismic events and seismic ambient noise allowed us to retrieve a shear wave velocity model, whose seismic structure appears to be highly consistent with independent results published in previous studies.

For a wide range of periods (from 5 to $30 \mathrm{~s}$ ), the phase velocities of the study area turned out to be systematically higher than those measured for the Italian peninsula, suggesting a colder geotherm. A methodical evaluation of the uncertainty affecting our data allowed us to discriminate the robust features of the final model. Whereas at crustal depths we observe relatively low standard deviations; larger uncertainties at long periods restrict the reliable seismic images to the study area below Sardinia and southern Corsica.

The lateral variations of the $V_{S}$ in the upper crust closely resemble the geology of the study area, highlighting the velocity contrast between the outcropping Variscan basement and the more recent units. Remarkably, we found the middle and the lower crust to be rather homogeneous, bearing no sign of the Miocene volcanism. At greater depths, an inhomogeneous seismic structure suggests an heterogeneous lithospheric mantle. Interestingly, the lateral variations we observe would be consistent with the hypothesis of a Mediterranean plume-like body, suggested by several authors on geochemical arguments. The high absolute velocities characterizing the crust, together with the temperatures we estimated, induce us to rule out this idea, even though a larger-scale geophysical study would be needed in order to resolve such a deep structure and unravel its nature.

The absolute values of the $V_{S}$ also allow us to directly constrain the depth of the LAB (that we locate at $\sim 100 \mathrm{~km}$ ). Remarkably, this result suggests that most of the Sardinian lithosphere endured the complex history of deformation experienced by the study area and has general implications on the ability of lithospheric fragments to be preserved despite the interaction with deeper processes.

\section{ACKNOWLEDGEMENTS}

Our many exchanges with Emanuel Kästle were very beneficial to this study. We are grateful to two anonymous reviewers and the editor Ian Bastow for carefully reading and commenting our manuscript. We also thank the University of Twente for funding the installation and maintenance of the LiSard stations. The Grant to Department of Science, Roma Tre University (MIUR-Italy Dipartimenti di Eccellenza, ARTICOLO 1, COMMI 314-337 LEGGE $232 / 2016$ ) is gratefully acknowledged.

\section{REFERENCES}

Aki, K., 1957. Space and time spectra of stationary waves with special reference to microtremors, Bull. Earthq. Res. Inst. Univ. Tokyo, 35, 415456.

Alvarez, W., 1972. Rotation of the Corsica-Sardinia microplate, Nat. Phys. Sci., 236, 103-105.

Behn, M.D. \& Kelemen, P.B., 2003. Relationship between seismic $P$-wave velocity and the composition of anhydrous igneous and meta-igneous rocks, Geochem. Geophys. Geosyst., 4(5), doi:10.1029/2002GC000393.

Bell, K., Lavecchia, G. \& Rosatelli, G., 2013. Cenozoic Italian magmatismisotope constraints for possible plume-related activity, J. South Am. Earth Sci., 41, 22-40.

Bensen, G.D., Ritzwoller, M.H., Barmin, M.P., Levshin, A.L., Lin, F., Moschetti, M.P., Shapiro, N.M. \& Yang, Y., 2007. Processing seismic ambient noise data to obtain reliable broad-band surface wave dispersion measurements, Geophys. J. Int., 169(3), 1239-1260 .

Boschi, L. \& Dziewonski, A.M., 1999. High- and low-resolution images of the Earth's mantle: implications of different approaches to tomographic modeling, J. geophys. Res., 104(B11), 25 567-25 594.

Boschi, L. \& Weemstra, C., 2015. Stationary-phase integrals in the cross-correlation of ambient noise, Rev. Geophys., 53, doi:10.1002/2014RG000455.

Boschi, L., Weemstra, C., Verbeke, J., Ekström, G., Zunino, A. \& Giardini, D., 2013. On measuring surface wave phase velocity from stationstation cross-correlation of ambient signal, Geophys. J. Int., 192(1), 346-358 . 
Cammarano, F. \& Guerri, M., 2017. Global thermal models of the lithosphere, Geophys. J. Int., 210, 56-72.

Cammarano, F., Goes, S., Vacher, P. \& Giardini, D., 2003. Inferring upper mantle temperatures from seismic velocities, Phys. Earth planet. Inter., 139, 197-222.

Cammarano, F., Tackley, P. \& Boschi, L., 2011. Seismic, petrological and geodynamical constraints on thermal and compositional structure of the upper mantle: global thermochemical models, Geophys. J. Int., 187, 13011318.

Carmignani, L., Oggiano, G., Funedda, A., Conti, P. \& Pasci, S., 2016. The geological map of Sardinia (Italy) at 1:250,000 scale, J. Maps, 12, $826-835$.

Carminati, E., Lustrino, M. \& Doglioni, C., 2012. Geodynamic evolution of the central and western Mediterranean: tectonics vs. igneous petrology constraints, Tectonophysics, 579, 173-192.

Cassidy, D.C., Holton, G. \& Rutherford, F.J., 2002. Understanding Physics, Springer Science \& Business Media.

Christensen, N.I., 1996. Poisson's ratio and crustal seismology, J. geophys. Res., 101(B2), 3139-3156.

Christensen, N.I. \& Mooney, W.D., 1995. Seismic velocity structure and composition of the continental crust: a global view, J. feophys. Res., 100(B6), 9761-9788.

Corti, G., Cuffaro, M., Doglioni, C., Innocenti, F. \& Manetti, P., 2006. Coexisting geodynamic processes in the Sicily Channel, Geol. Soc. Am., 409, 83-96.

Cuccuru, S., Oggiano, G. \& Funedda, A., 2015. Low enthalpy geothermal suitability of North Sardinia (Italy), Energy Procedia, 76, 256-263.

Di Stefano, R., Bianchi, I., Ciaccio, M.G., Carrara, G. \& Kissling, E., 2011. Three-dimensional Moho topography in Italy: new constraints from receiver functions and controlled source seismology, Geochem. Geophys. Geosyst., 12(9), 1-15.

Egger, A., Demartin, M., Ansorge, J., Banda, E. \& Maistrello, M., 1988. The gross structure of the crust under Corsica and Sardinia, Tectonophysics, 150(3), 363-389.

Ekström, G., Abers, G.A. \& Webb, S.C., 2009. Determination of surfacewave phase velocities across USArray from noise and Aki's spectral formulation, Geophys. Res. Lett., 36, doi:10.1029/2009GL039131 .

Faccenna, C., Speranza, F., Caracciolo, F., Mattei, M. \& Oggiano, G., 2002. Extensional tectonics on Sardinia (Italy): insights into the arc back-arc transitional regime, Tectonophysics, 356(4), 213-232.

Faccenna, C. et al., 2014. Mantle dynamics in the Mediterranean, Rev. Geophys., 52, 283-332.

Gasperini, D., Blichert-Toft, J., Bosch, D., Del Moro, A., Macera, P., Tlouk, P. \& Albarde, F., 2000. Evidence from Sardinian basalt geochemistry for recycling of plume heads into the Earth's mantle, Nature, 408, 701-704.

Gasperini, D., Blichert-Toft, J., Bosch, D., Del Moro, A., Macera, P., Tlouk, P. \& Albarde, F., 2002. Upwelling of deep mantle material through a plate window: evidence from the geochemistry of Italian basaltic volcanics, $J$. geophys. Res., 107, 1-19.

Greve, S., Paulssen, H., Goes, S. \& van Bergen, M., 2014. Shear-velocity structure of the Tyrrhenian Sea: tectonics, volcanism and mantle (de) hydration of a back-arc basin, Earth planet. Sci. Lett., 400, 45-53.

Gung, Y., Panning, M. \& Romanowicz, B., 2003. Global anisotropy and the thickness of continents, Nature, 422(6933), 707-711.

Hansen, P., 2001. The L-curve and its use in the numerical treatment of inverse problems, in Computational Inverse Problems in Electrocardiology, Vol. 5, pp. 119-142, ed. Johnston, P., WIT Press.

Jin, G. \& Gaherty, J.B., 2015. Surface wave phase-velocity tomography based on multichannel cross-correlation, Geophys. J. Int., 201, 13831398.

Jolivet, L., Faccenna, C. \& Piromallo, C., 2009. From mantle to crust: stretching the Mediterranean, Earth planet. Sci. Lett., 285, 198-209.

Kästle, E., Soomro, R., Weemstra, C., Boschi, L. \& Meier, T., 2016. Tworeceiver measurements of phase velocity: cross-validation of ambientnoise and earthquake-based observations, Geophys. J. Int., 207, 14931512.

Kästle, E., El-Sharkawy, A., Boschi, L., Meier, T., Rosenberg, C.L., Bellahsen, N., Cristiano, L. \& Weidle, C., 2018. Surface-wave tomography of the
Alps using ambient-noise and earthquake phase-velocity measurements, J. geophys. Res., 123, doi:10.1002/2017JB014698 .

Köhler, A., Weidle, C. \& Maupin, V., 2012. Crustal and uppermost mantle structure of southern Norway: results from surface wave analysis of ambient seismic noise and earthquake data, Geophys. J. Int., 191(3), $1441-1456$.

Lavecchia, G. \& Creati, N., 2006. A mantle plume head trapped in the transition zone beneath the Mediterranean: a new idea, Ann. Geophys., 49, 373-387.

Lin, F.-C., Moschetti, M.P. \& Ritzwoller, M.H., 2008. Surface wave tomography of the western United States from ambient seismic noise: Rayleigh and Love wave phase velocity maps, Geophys. J. Int., 173(1), 281-298

Lin, F.C., Ritzwoller, M.H. \& Snieder, R., 2009. Eikonal tomography: surface wave tomography by phase front tracking across a regional broadband seismic array, Geophys. J. Int., 177(3), 1091-1110.

Lu, Y., Stehly, L., Paul, A. \& Group, A.W., 2018. High-resolution surface wave tomography of the European crust and uppermost mantle from ambient seismic noise, Geophys. J. Int., 214(2), $1136-1150$.

Lustrino, M., 2013. Origin and evolution of Cenozoic magmatism of Sardinia (Italy). A combined isotopic ( $\mathrm{Sr}-\mathrm{Nd}-\mathrm{Pb}-\mathrm{O}-\mathrm{Hf}-\mathrm{Os}$ ) and petrological view, Lithos, 180, 138-158.

Lustrino, M., Duggen, S. \& Rosenberg, C.L., 2011. The Central-Western Mediterranean: anomalous igneous activity in an anomalous collisional tectonic setting, Earth-Sci. Rev., 104, 1-40.

Ma, Y. \& Clayton, R.W., 2014. The crust and uppermost mantle structure of Southern Peru from ambient noise and earthquake surface wave analysis, Earth planet. Sci. Lett., 395, 61-70.

Malusá, M.G., Danišík, M. \& Kuhlemann, J., 2016. Tracking the Adriatic-slab travel beneath the Tethyan margin of CorsicaSardinia by low-temperature thermochronometry, Gondwana Res., 31, 135-149.

Martin-Short, R., Allen, R., Bastow, I.D., Porritt, R.W. \& Miller, M.S., 2018. Seismic imaging of the Alaska subduction zone: implications for slab geometry and volcanism, Geochem. Geophy. Geosy., 19, $4541-4560$.

Meier, T., Dietrich, K., Stöckhert, B. \& Harjes, H.P., 2004. One-dimensional models of shear wave velocity for the eastern Mediterranean obtained from the inversion of Rayleigh wave phase velocities and tectonic implications, Geophys. J. Int., 156(1), 45-58.

Molinari, I., Verbeke, J., Boschi, L., Kissling, E. \& Morelli, A., 2015. Italian and Alpine three-dimensional crustal structure imaged by ambient-noise surface-wave dispersion, Geochem. Geophys. Geosyst., 16(12), 44054421.

Oggiano, G., Funedda, A., Carmignani, L. \& Pasci, S., 2009. The SardiniaCorsica microplate and its role in the Northern Apennine Geodynamics: new insights from the Tertiary intraplate strike-slip tectonics of Sardinia, Ital. J. Geosci., 128, 527-539.

Panza, G.F., Peccerillo, A., Aoudia, A. \& Farina, B., 2007. Geophysical and petrological modelling of the structure and composition of the crust and upper mantle in complex geodynamic settings: the Tyrrhenian Sea and surroundings, Earth-Sci. Rev., 80, 1-46.

Paternoster, M., Oggiano, G., Sinisi, R., Caracausi, A. \& Mongelli, G., 2017. Geochemistry of two contrasting deep fluids in the Sardinia microplate (western Mediterranean): relationships with tectonics and heat sources, $J$. Volc. Geotherm. Res., 336, 108-117.

Ritzwoller, M.H., Lin, F.C. \& Shen, W., 2011. Ambient noise tomography with a large seismic array, C. R. Geosci., 343(8), 558-570.

Scrocca, D., Doglioni, C. \& Innocenti, F., 2003. Constraints for an interpretation of the Italian geodynamics: a review, Mem. Descr. Carta Geol. d'It, 62, 15-46.

Seats, K.J., Lawrence, J.F. \& Prieto, G.A., 2012. Improved ambient noise correlation functions using Welch's method, Geophys. J. Int., 188, 513523 .

Seber, D., Barazangi, M., Ibenbrahim, A. \& Demnati, A., 1996. Geophysical evidence for lithospheric delamination beneath the Alboran Sea and RifBetic mountains, Nature, 379(6568), 785-790. 
Shapiro, N.M. \& Ritzwoller, M.H., 2004. Thermodynamic constraints on seismic inversions, Geophys. J. Int., 157(3), 1175-1188.

Shapiro, N.M., Campillo, M., Stehly, L. \& Ritzwoller, M.H., 2005. Highresolution surface-wave tomography from ambient seismic noise, Science, 307(5715), 1615-1618.

Soomro, R., Weidle, C., Cristiano, L., Lebedev, S. \& Meier, T., 2016. Phase velocities of Rayleigh and Love waves in central and northern Europe from automated, broad-band, interstation measurements, Geophys. J. Int., 204(1), 517-534.

Speranza, F., Villa, I.M., Sagnotti, L., Florindo, F., Cosentino, D., Cipollari, P. \& Mattei, M., 2002. Age of the Corsica-Sardinia rotation and Liguro-Provencal Basin spreading: new paleomagnetic and Ar/Ar evidence, Tectonophysics, 347, 231-251. van der Meijde, M., van der Lee, S. \& Giardini, D., 2003. Crustal structure beneath broad-band seismic stations in the Mediterranean region, Geophys. J. Int., 152, 729-739.

Wortel, M.J.R. \& Spakman, W., 2000. Subduction and slab detachment in the Mediterranean-Carpathian region, Science, 290(5498), 1910-1917.

Yang, Y., Shen, W. \& Ritzwoller, M.H., 2011. Surface wave tomography on a large-scale seismic array combining ambient noise and teleseismic earthquake data, Earthq. Sci., 24(1), 55-64.

Yoshizawa, K. \& Kennett, B., 2002. Determination of the influence zone for surface wave paths, Geophys. J. Int., 149(2), 440-453.

Zhou, L., Xie, J., Shen, W., Zheng, Y., Yang, Y., Shi, H. \& Ritzwoller, M.H., 2012. The structure of the crust and uppermost mantle beneath South China from ambient noise and earthquake tomography, Geophys. J. Int., 189(3), 1565-1583. 